\title{
Suspension Hammering Tester for Concrete Walls
}

\author{
Saeko Tokuomi ${ }^{1}$, Kazuya Mori ${ }^{1}$ \\ ${ }^{1}$ Kumamotoy University \\ 2-39-1 Kurokami, Chuo-ku Kumamoto, Japan \\ stokuomi@mech.kumamoto-u.ac.jp; kmori@mech.kumamoto-u.ac.jp
}

\begin{abstract}
Inspection method of concrete structures is typically hammering test. In the hammering test workers tap surfaces of concrete with a hammer. However, workers' testing is not economical in both time and money. So we have developed a suspension hammering tester for concrete walls which includes an impact acoustic apparatus to detect defects. The tester ascends/descends by a winch mounted to the rooftop of buildings, ascending/descending at a speed of $0.5 \mathrm{~m} / \mathrm{s}$. The tester has four wheels, four impactors, two microphones, and four fans that apply pressure in order for the machine to adhere to concrete walls. Four impactors are positioned at equal intervals of $150 \mathrm{~mm}$ on a horizontal axis combining to create a $0.5 \mathrm{~m}$ wide testing range during a single ascent or descent. So, the testing speed is 0.5 $\mathrm{m} / \mathrm{s} * 0.5 \mathrm{~m}=0.25 \mathrm{~m} / \mathrm{s}^{2}$. The dimensions of the machine are $70 \mathrm{~cm}$ wide, $80 \mathrm{~cm}$ long and $18 \mathrm{~cm}$ thick.
\end{abstract}

Keywords: Non-destructive Testing, Hammering Test, Concrete Wall, Suspension Tester.

\section{Introduction}

A lot of concrete structures are deteriorating to dangerous levels throughout the world. These concrete structures need to be inspected regularly to be sure that they are safe enough to be used. The inspection method of these concrete structures is typically the impact acoustic method. In the impact acoustic method the worker taps the surface of the concrete with a hammer. So it is usually necessary to set up scaffolding to access vertical structures for inspection. However, setting up of high scaffolding is not economical in both time and money. Therefore, there is an urgent need for an economical solution to this problem of testing.

Some methods of testing in high places have already been attempted. Using drones is one such method that has been attracting attention [1]. However, drones are probably affected by winds. Wall climbing robots have also been developed [2] but they were too slow to be practical.

So we have developed a suspension hammering tester as shown in Fig. 1. This tester ascends/descends vertical concrete walls with the aid of a winch mounted to the roof. While ascending/descending, the impact acoustic method tests for defects. The effectiveness of the impact acoustic apparatus was investigated on a dummy concrete wall.

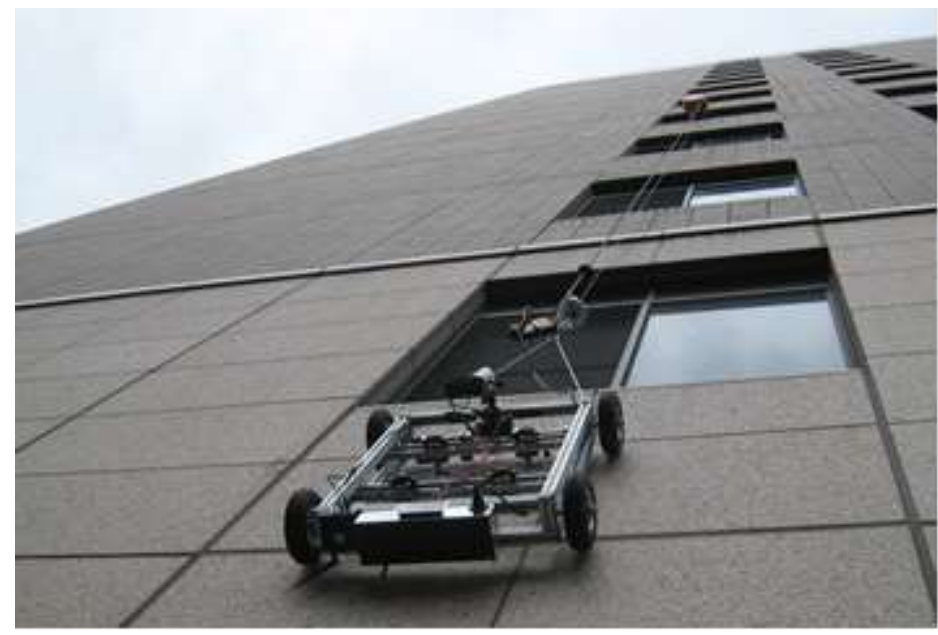

Fig. 1: Suspension Hammering Tester on a concrete wall. 


\section{Suspension Hammering Tester \\ 2.1. Design of Hammering Tester}

Figure 2 shows the design of the suspension hammering tester that we have developed. This tester ascends/descends from the rooftop of buildings by a winch at a speed of $0.5 \mathrm{~m} / \mathrm{s}$. The tester has four wheels, four impactors, two microphones, and four fans that apply pressure in order for the tester to adhere to concrete walls. The initial prototype had two bladed fans with a diameter of 7 inches and a pitch of 5 inches.

The four fans can be controlled independently enabling the machine to constantly be placed in the correct position regardless of angles and obstacle especially windows. Four impactors are positioned at equal intervals of $150 \mathrm{~mm}$ on a horizontal axis combining to create a $0.5 \mathrm{~m}$ wide testing range during a single ascent or descent. So, the testing speed is $0.5 \mathrm{~m} / \mathrm{s} * 0.5 \mathrm{~m}=0.25 \mathrm{~m} / \mathrm{s}^{2}$. The acoustic sound picked up by the microphones is sent to the operator by a transmitter along with live video footage. Power is supplied through electrical cables from the rooftop. The dimensions of the machine are $70 \mathrm{~cm}$ wide, $80 \mathrm{~cm}$ long and $18 \mathrm{~cm}$ thick. The weight of the machine is $14.2 \mathrm{~kg}$.

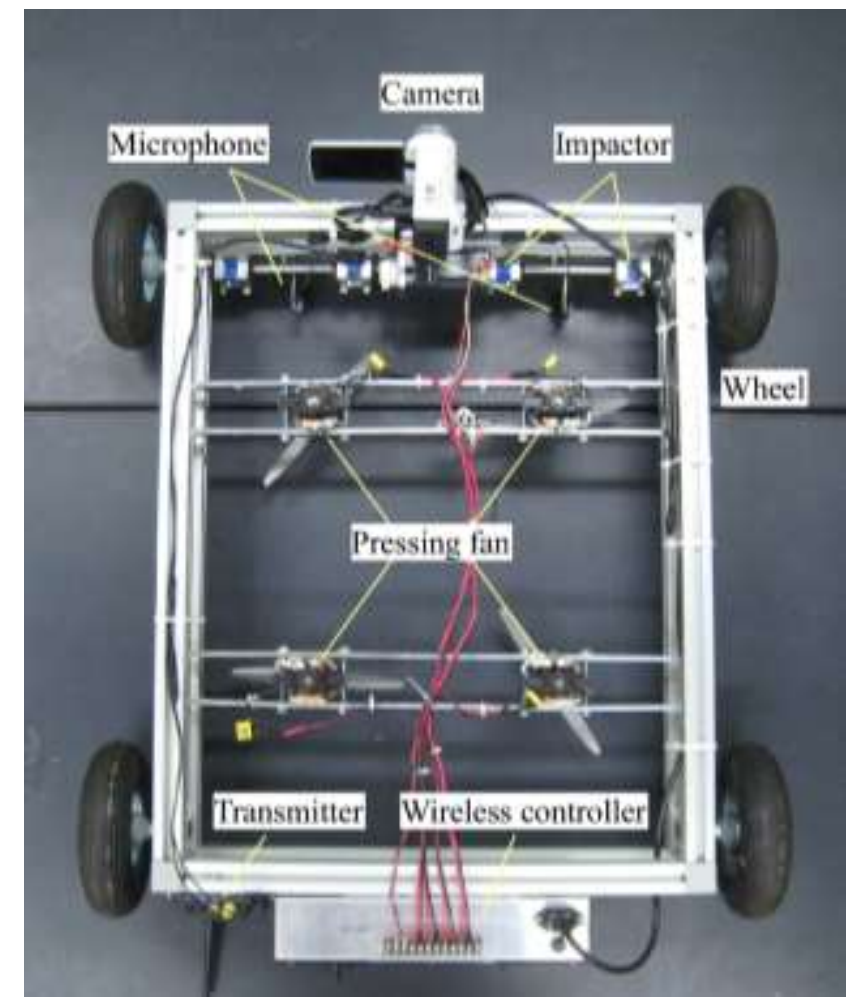

Fig. 2: Suspension Hammering Tester with dimensions of $70 \mathrm{~cm}$ by $80 \mathrm{~cm}$.

\subsection{Impactors}

Figure 3 shows the impactor mounted on the frame of the testing machine. The impactor unit has a hammer weighing $33 \mathrm{~g}$ driven by a circular cam. The impact frequency of the hammer is $5 \mathrm{~Hz}$ and the hammer impacts the wall every 10 $\mathrm{cm}$ as it rappels at a speed of $0.5 \mathrm{~m} / \mathrm{s}$. As only two microphones are used, the cams are set 90 degrees apart so that the timing of the impacts alternate and isolate the impact sounds.

\section{Impact Acoustic Test}

The noise of fans used in non-destructive testing methods such as drones is a serious problem. As our tester also includes fans position near the microphones this problem had to be addressed as shown in Fig. 2. The mitigation of sound pollution was a major area in the development of our tester.

Figure 4 shows the frequency spectrum of the impact sound on the dummy concrete wall while the fans were stationary. The frequency peaks at $0.2 \mathrm{kHz}$ indicating the natural frequency of the testing wall. 

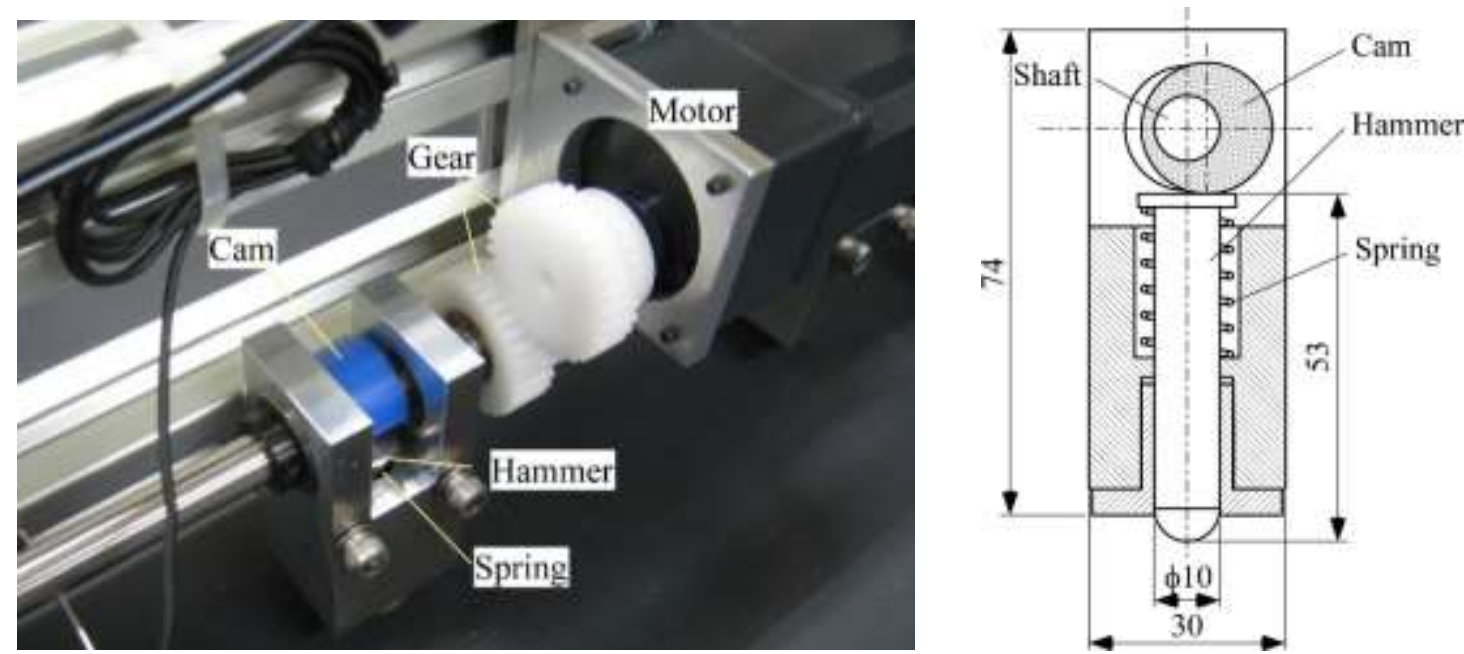

Fig. 3: Picture and cross-section drawing of the impactor.

Figure 5 shows the frequency spectrum of the impact sound on the dummy concrete wall while the fans were in operation. The peak at $0.55 \mathrm{kHz}$ as well as the peaks at higher harmonics are all caused by the fans. The fundamental frequency peak at $0.55 \mathrm{kHz}$ is five times greater in amplitude than the peak of the impact sound at $0.2 \mathrm{kHz}$. As can be seen in Fig. 5, impact frequency may be hidden by the peak frequencies of the fans. The problem is the sound level of the fans, as well as the frequency. So, an acoustic shield made of polystyrene foam was installed between the microphones and the fans to reduce the fan noise. Moreover, eight-bladed fans were introduced to shift the fan frequency.

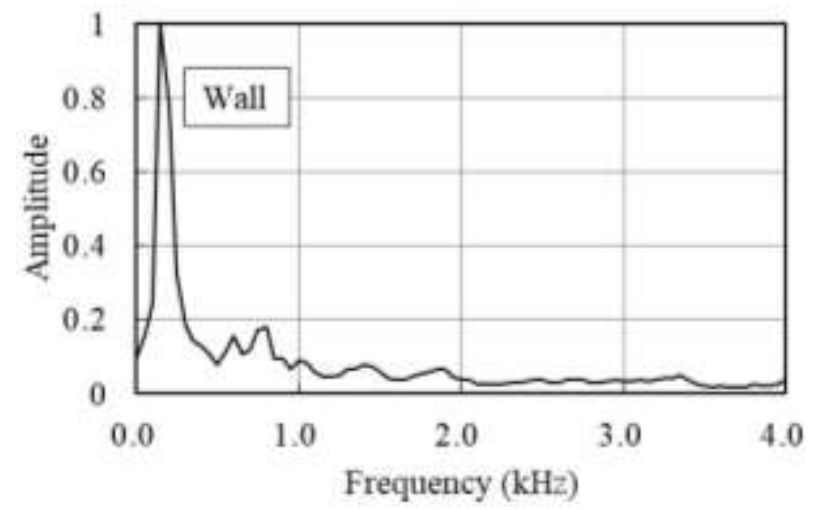

Fig. 4: The frequency spectrum of the impact sound on the test concrete wall under fans in stationary.

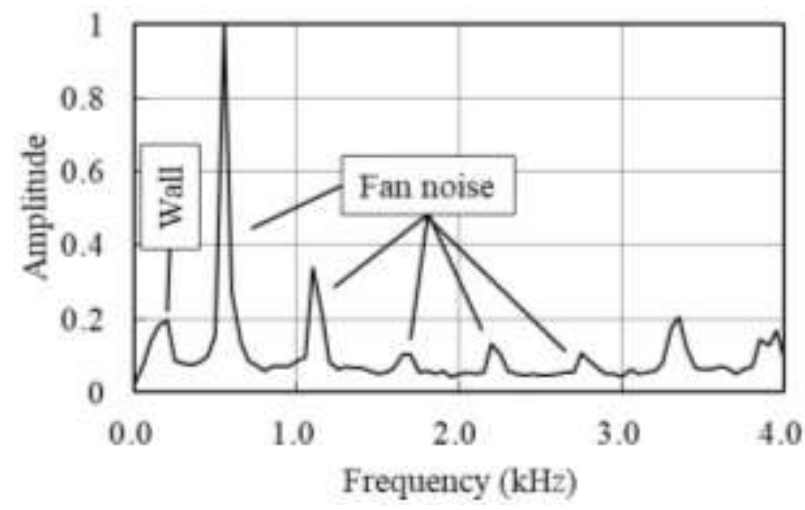

Fig. 5: The frequency spectrum of the impact sound on the test concrete wall under fans in operation. 
The fundamental frequency of the fan noise, $f_{F}$ is determined by the fan's rotation speed, $n$ (rps) and the number of the blades, $b$;

$$
f_{F}=n \cdot b(\mathrm{~Hz})
$$

In Fig. 5 the fundamental frequency of the fans was $f_{F}=0.55 \mathrm{kHz}$. Therefore, the rotation speed was $n=f_{F} / b=$ $550(\mathrm{~Hz}) / 2$ blades $=275 \mathrm{rps}=16500 \mathrm{rpm}$. From Eq. (1), the fundamental frequency, $f_{F}$ rises when either the rotation speed of the fans is increased, $n$ or the number of the blades, $b$ is increased. Unfortunately, the rotational speed of 16 $500 \mathrm{rpm}$ is close to the limit for light-weight electric motors so increasing speed isn't an option. So, experimenting with the number of blades became the only course of action. So, eight-bladed fans made using a 3D printer were trailed.

The results of the eight bladed fans are shown in Fig. 6. As can be seen in Fig. 6, the fundamental frequency of the fan noise increased to $2.5 \mathrm{kHz}$, and there are no significant peaks in the region between $0 \mathrm{kHz}$ and $2.5 \mathrm{kHz}$ excluding the impact sound. The peak of the impact sound can be clearly distinguished. This result indicates that the increase in fan blade number is effective in the accuracy of the testing because the frequency of the fans then falls outside the range of the defect.

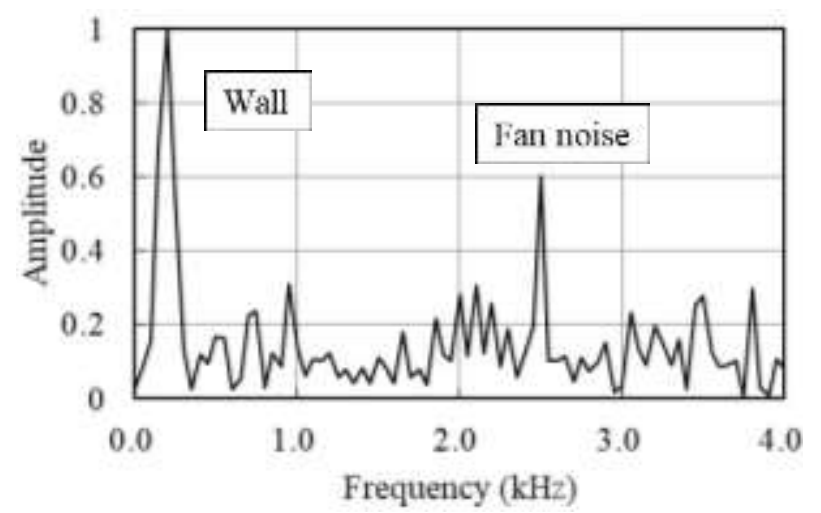

Fig. 6: The frequency spectrum of the eight bladed fan with an acoustic shield.

\section{Conclusion}

A suspension hammering tester has been developed. The tester is able to adhere to, rappel down and ascend/descend vertical walls using a winch and fans while testing for defects. According to the results, we conclude as follows;

(1) The machine is able to make ascents/descents of vertical walls at a speed of $0.5 \mathrm{~m} / \mathrm{s}$, and is unimpeded by obstacles such as windows by controlling the fans.

(2) The testing range during a single ascent/descent is $0.5 \mathrm{~m}$ in width, creating a test speed of $0.25 \mathrm{~m}^{2} / \mathrm{s}$.

(3) The increase in the number of fan blades increases the frequency. In this paper, eight-bladed fans pushed the frequency of the fan noise passed $2.0 \mathrm{kHz}$ and therefore outside the frequency range of defects.

\section{Acknowledgements}

This work was supported by JSPS KAKENHI Grant Number JP17K06536. We would also like to express our gratitude to JSPS for their financial support.

\section{References}

[1] Advanced Highway Maintenance and Construction Program, University of California at Davis, "CALTRANS Bridge Inspection Aerial Robot," Report No. CA08-0182, 2008, pp. 1-26.

[2] S. Tokuomi, K. Mori, Y. Tsuruzono, "Concrete-Wall-Climbing Testing Robot," World Academy of Science, Engineering and Technology, vol. 9, no. 10, pp. 465-469, 2015. 